\title{
The 3-M syndrome: risk of intracerebral aneurysm?
}

\author{
R F Mueller, J Buckler, R Arthur, G Bonsor, P Dear, K Walters, G M Towns
}

\begin{abstract}
We describe a child with typical features of the 3-M syndrome who presented with acute hydrocephalus owing to haemorrhage from one of two intracranial cerebral vascular aneurysms. We suggest that other children with this disorder should be screened for similar complications.
\end{abstract}

Miller et $a l^{1}$ described in 1975 a distinct form of dwarfism which was named after the initials of the first three authors and has been further characterised as consisting of pre- and postnatal growth retardation, a triangular facies, a dolichocephalic or 'hatchet shaped' skull, prominent heels, joint hypermobility, and slender ribs and long bones on $x$ ray. $^{2-8}$

\section{Case reports}

The proband was the first child of unrelated parents, born by caesarian section at 32 weeks after a pregnancy complicated by mild maternal hypertension, low oestriols, and poor fetal growth. His birth weight was $850 \mathrm{~g}(<3 \mathrm{rd}$ centile), head circumference $26.4 \mathrm{~cm}(<3 \mathrm{rd}$ centile), and length $35 \mathrm{~cm}$ ( $<3$ rd centile). He developed mild respiratory distress for which he received minimal ventilatory support for two days. He was noted at the time to have an odd shaped skull and dysmorphic facies and was thought to have relatively short limbs. He was tube fed for seven weeks but went on to establish feeding and was discharged home at 10 weeks of age.

His subsequent growth was parallel to but well below the normal centiles. A bone age done at 9 months of age was compatible with that of a newborn. Early developmental milestones were appropriate when corrected for his prematurity.

When reviewed at 6 years of age he was noted to have proportionate short stature (fig 1), a narrow facies (fig 2) with a 'hatchet shaped' skull, and marked joint hypermobility. A skeletal survey showed slender bones and a dolichocephalic skull (fig 3). These features were all consistent and typical of the $3 \mathrm{M}$ syndrome.

At the age of $8 \frac{1}{2}$ years he suddenly developed a severe headache, collapsed, and had what was thought to be a generalised seizure. Three more episodes were witnessed and felt to be because of acute hydrocephalus. He required intubation and ventilation. Cranial CT scan showed blood in the fourth, third, and lateral ventricles and acute hydrocephalus. Subsequent cerebral angiography showed a left posterior inferior cerebellar artery (PICA) (fig 4) aneurysm which was the source of the haemorrhage. In addition, there was a sessile intracavernous carotid aneurysm on the right side (fig 5).

A right frontal external ventricular drain was inserted and two days later a posterior fossa craniotomy was performed and the left PICA aneurysm was clipped. He recovered well and was weaned off the ventilator within 48 hours. Two weeks later a medium pressure right sided ventriculoperitoneal shunt was inserted; 48 hours later fever and abdominal tenderness developed. The ventriculoperitoneal shunt was removed and a ventricular drain was reinserted. Laparotomy and abdominal toilet were performed showing free pus in the peritoneal cavity. Postoperatively, intravascular coagulation and respiratory distress ensued and he deteriorated and died four days later.

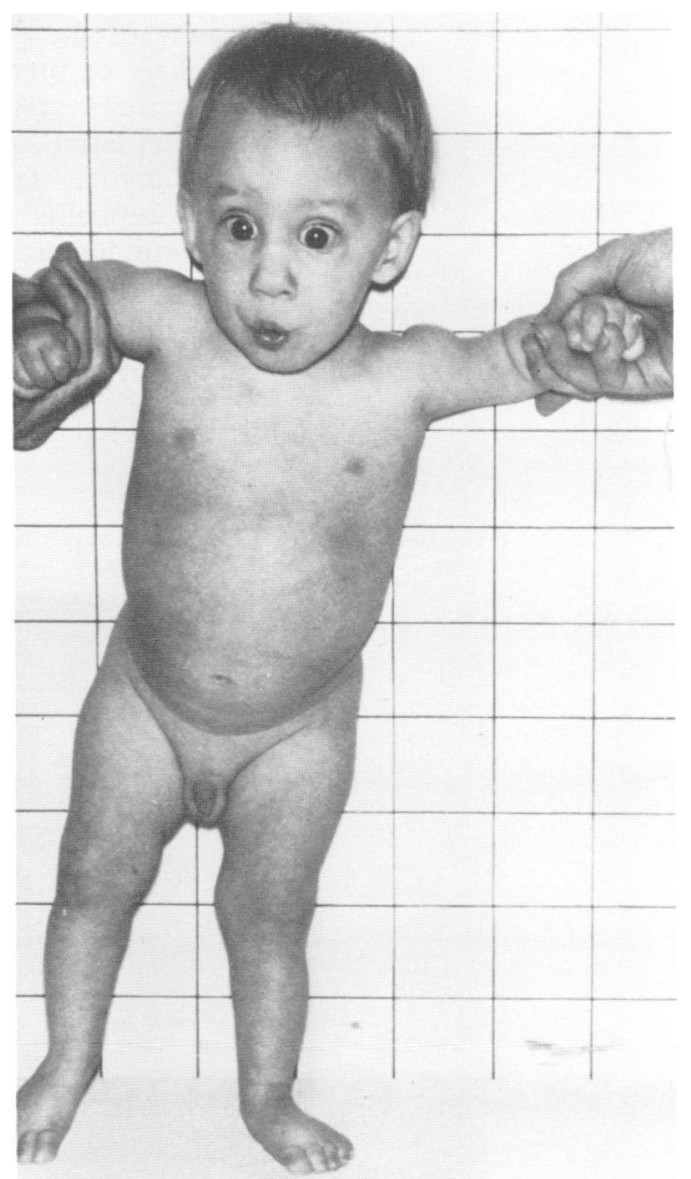

Figure 1 The proband showing proportionate short stature.
Received 4 July 1991. Revised version accepted 23 September 1991. 


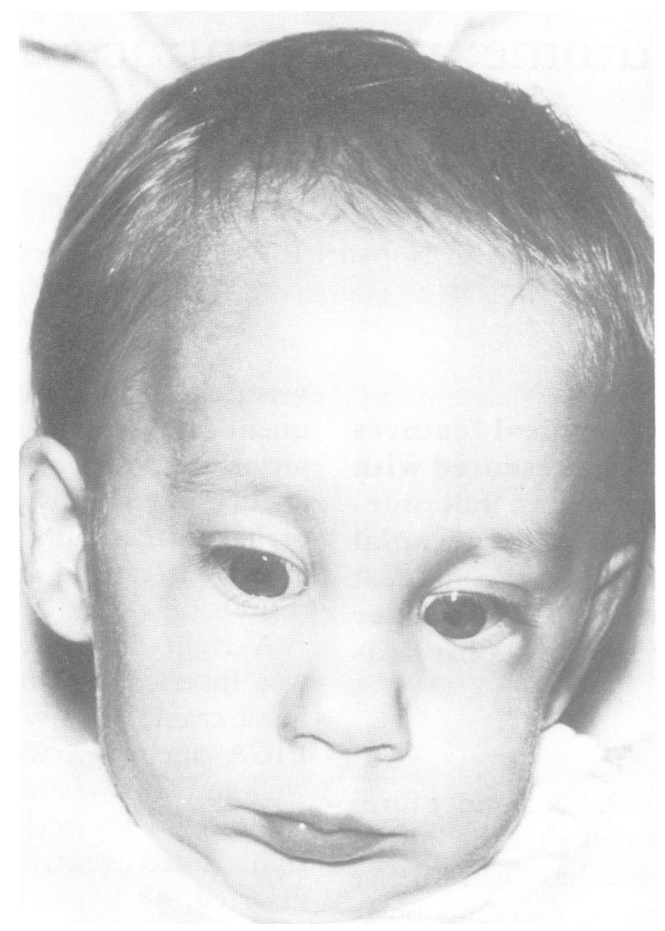

Figure 2 Facies of the proband.

\section{Discussion}

3-M dwarfism is one of a number of primordial dwarfing syndromes. It can be distinguished from many of the others by the absence of microcephaly or mental retardation. Characteristic features include pre- and postnatal growth retardation, proportionate short stature, a triangular facies, a 'hatchet-shaped' or dolichocephalic skull, prominent heels, marked joint hypermobility and slender ribs and long bones on $x$ ray..$^{1-8}$

The joint hypermobility, the highly unusual feature of intracerebral vascular aneurysms in a child of this age, along with a number of the children reported having had joint dislocations,

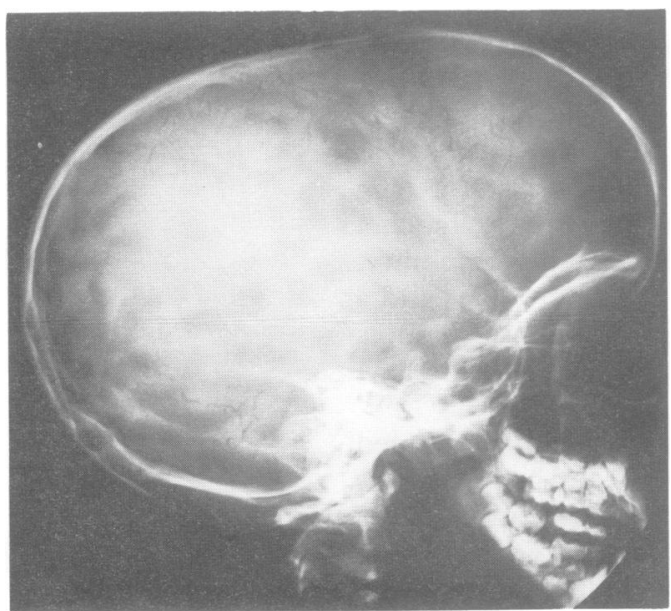

Figure 3 Lateral $x$ ray of the skull showing dolichocephaly.

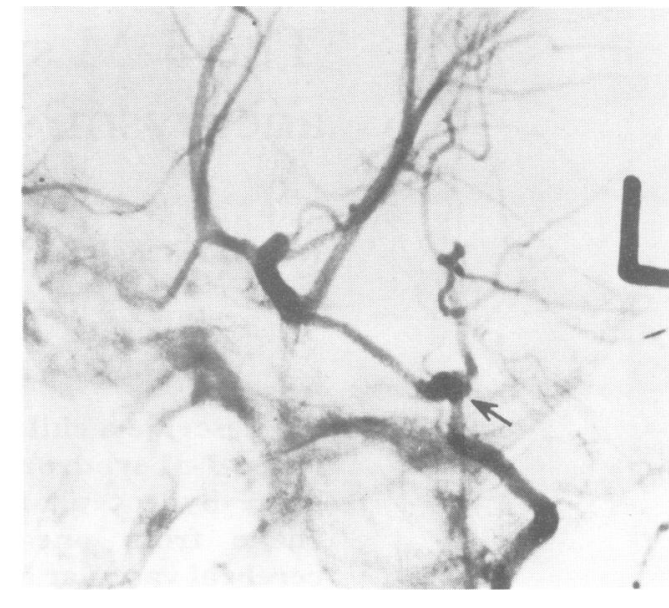

Figure 4 Subtraction film of an oblique occipitomental view of cerebral angiography of the proband showing the left posterior inferior cerebellar artery aneurysm (arrowed).

all suggest the possibility that the $3-M$ syndrome may be a generalised disorder of connective tissue. Although controversial, reports of deficiency of type III collagen in some patients with ruptured cerebral aneurysms supports this suggestion. ${ }^{9-14}$ We are unaware of any biochemical or DNA studies looking at any of the collagen or any of the other connective tissue proteins in any children with the 3-M syndrome and suggest that surviving children with the 3-M syndrome could be investigated for this possibility.

In addition, although it is not clear from this single case report whether the intracerebral vascular abnormalities were coincidental or an associated fearure of the 3-M syndrome, the potential morbidity and mortality which might

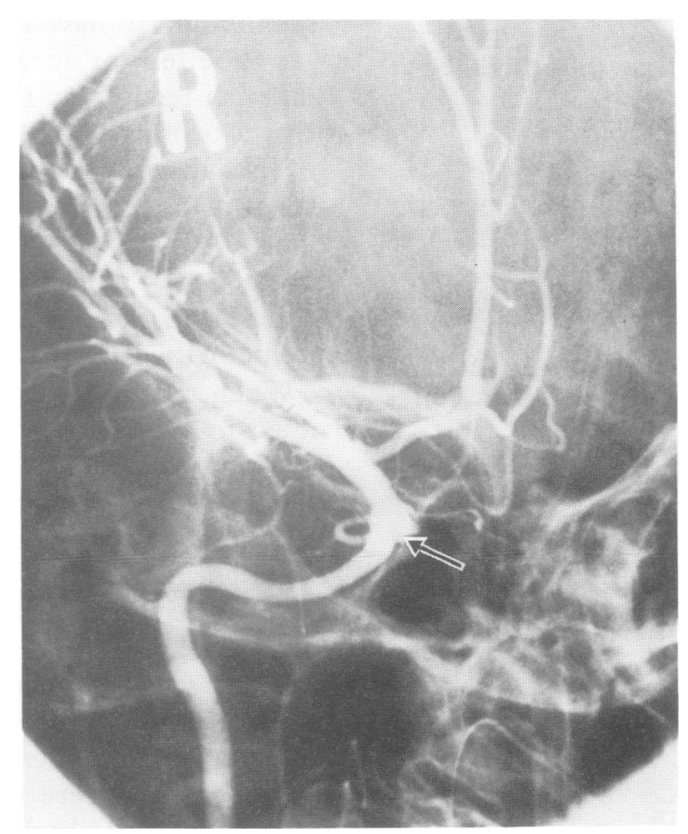

Figure 5 An oblique perorbital view of cerebral angiography of the proband showing the sessile intracavernous carotid aneurysm (arrowed). 
be improved by elective surgery warrants serious consideration of investigation by an appropriate non-invasive means, such as magnetic resonance angiography.

1 Miller JD, McKusick VA, Malvaux P, Temtamy S, Salinas $S$. The 3-M syndrome: a heritable low birth-weight dwarfism. Birth Defects 1975;XI(5):39-47.

2 Fuhrmann $\mathbb{W}$, Nägele E, Gagler R, Adili E. Familiare Minderwuchs mit unproportioniert hohen Wirbeln. Humangenetik 1972;16:271-82.

3 Spranger J, Opitz JM, Nourmand A. A new familial growth retardation syndrome. The ' $3-\mathrm{M}$ syndrome'. Eur $f$ Pediatr 1976;123:115-24.

4 Garcia-Cruz D, Cantú JM. Heterozygous expression in 3-M slender-boned nanism. Hum Genet 1979;52:221-6.

5 Cantú JM, Garcia-Cruz D, Sanchez-Corona J, Fragoso R, Hernández A, Nazará-Cazorla Z. 3-M slender-boned nanism. An intrauterine growth retardation syndrome. Am $\mathcal{F}$ Dis Child 1981;135:905-8.
6 Winter RM, Baraitser M, Grant DB, Preece MA, Hall CM. The 3-M syndrome. 7 Med Genet 1984;21:124-8.

7 Hennekam RCM, Bijlsma JB, Spranger J. Further delineation of the 3-M syndrome with review of the literature. Am $\mathcal{F}$ Med Genet 1987;28:195-209.

8 Feldmann M, Gilgenkrantz S, Parisot S, Zarini G, Marchal C. $3 M$ dwarfism: a study of two further sibs. 7 Med Genet 1989;26:583-5.

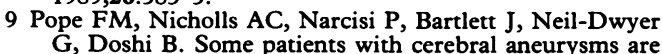
deficient in type III collagen. Lancet 1981;i:973-5.

10 Østergaard JR, Oxlund $H$. Collagen type III deficiency in patients with rupture of intracranial saccular aneurysms. f Neurosurg 1987;67:690-6.

11 Leblanc R, Lozano A, van der Rest $M$. Collagen deficiency in cerebral aneurysm. Stroke 1989;20:561.

12 Pope FM. Type III collagen mutations and cerebral aneurysms. Stroke 1989;20:1432.

13 Leblanc R, Lozano A, van der Rest M, Guttmann RD. Absence of collagen deficiency in familial cerebral aneurysms. F Neurosurg 1989;70:837-40.

14 Pope FM, Limburg M, Schievink WI. Familial cerebral aneurysms and type III collagen deficiency. $\mathcal{f}$ Neurosurg 1990;72:156-7. 